\title{
Extramedullary Hematopoiesis in a Non-Transfused Elderly Patient Diagnosed with Beta Thalassemia Minor
}

\author{
Buenasmañanas-Cervantes D*, Garcia-Torres E, Serrano-Lopez J, Arqueros-Martinez V, Rojas-Contreras \\ R and Sanchez-Garcia J
}

University Hospital Reina Sofia, Hematology Department, Instituto Maimonides Investigacion Biomedica, Spain

*Corresponding author: Buenasmañanas-Cervantes D, University Hospital Reina Sofia, Hematology Department, Instituto Maimonides Investigacion Biomedica (IMIBIC), Avd. Menendez Pidal S/N 14004 Córdoba, Spain, E-mail: diana84_bc@hotmail.com

Citation: Buenasmañanas-Cervantes D, Garcia-Torres E, Serrano-Lopez J, Arqueros-Martinez V, RojasContreras R, et al. (2015) Extramedullary Hematopoiesis in a Non-Transfused Elderly Patient Diagnosed with Beta Thalassemia Minor. J Hematol Blood Disord 1(1): 103. doi: 10.15744/2455-7641.1.103

Received Date: March 20, 2015 Accepted Date: August 03, 2015 Published Date: August 04, 2015

\begin{abstract}
Extramedullary hematopoiesis (EMH) is a compensatory reaction caused by the presence of hematopoietic precursors outside the bone marrow, ineffective erythropoiesis and patients with chronic hemolytic anemia. The most frequent cause of EMH is thalassemia intermedia, that produces an increase in demand of the hematopoietic system caused by anemia and is not reduced by transfusion therapy. We present a case of a man of 63 years with beta thalassemia minor, who had not received any transfusion, and that during three years presented a picture of progressive motor that was associated with loss of sensation in both legs deficit. After finding in nuclear magnetic resonance (NMR) an extradural intraspinal posterior lesion from D3 to D9, HE was diagnosed with EMH. The patient received radiation therapy to the affected area and gradually he recovered muscle strength of the lower limbs with rehabilitation exercises. This case report is exceptional due to the age at presentation (63 years old male) in a patient with beta thalassemia minor without transfusion requirements.
\end{abstract}

Keywords: Extramedullary hematopoiesis; Beta-thalassemia minor; Without transfusion requirements

\section{Introduction}

Extramedullary hematopoiesis (EMH) is a compensatory mechanism that leads to the production of blood cell precursors outside the marrow in patients with ineffective erythropoiesis and chronic hemolytic anemia [1]. The most frequent cause of EMH is thalassaemia intermedia-major, due to increased demand on the hematopoietic system from anemia not counterbalanced by transfusion support [2-5]. EMH can be located in many organs or tissues as the liver, spleen, lymph nodes and the epidural space, in the latter case leading to a spinal cord compression syndrome. In these instances, the clinical patterns are those of a lower dorsal spinal cord progressive compression secondary to an epidural expanding process. It can also be found at paravertebral, intrathoracic, intracranial or pelvic locations. Treatment options are controversial and include hypertransfusion, surgical excision, radiotherapy, and hydroxyurea [1,6].

\section{Case Report}

We present a case of EMH in a 63 years old male with a beta thalassemia minor MutC11(-T);GTT(Val GT-beta0 heterozigotous. Hemoglobin levels have been maintained in 10-11 gr/dl and never required transfusion support. The patient suffered of intermittent pain in the left thigh for the last three years, accompanied by muscle weakness. Motor deficit was progressive and associated with loss of sensitivity in the distal third of lower limbs, as well as frequency and urinary urgency. In the last month he needed two props for walking. He also referred sensation of numbness and upper abdominal tightness level. The patient did not refer symptoms in the upper limbs and cranial nerve affectation.

Physical examination revealed a lower limb hypertonia, more marked in the right leg and paraparesis of proximal predominance with hypoaesthesia at T7-T8 level. The blood count showed: Leukocytes 6.800/ $\mu \mathrm{L}, \mathrm{Hb} 10.9 \mathrm{gr} / \mathrm{dl}, \mathrm{MCV} 74$, platelets $174.000 / \mathrm{mm}^{3}$. Hemoglobin electrophoresis showed 3.5\% HbA2 and 1.2\% HbF.Total bilirubin $1.8 \mathrm{mg} / \mathrm{dl}$. PCR $19.6 \mathrm{mg} / \mathrm{l}, \mathrm{B} 2 \mathrm{microglobulin} 2083$ $\mathrm{g} / \mathrm{l}$. Complete biochemistry tests were in normal ranges.

Magnetic Resonance Image (MRI) imaging without contrast displayed a posterior extradural intraspinal polylobulated lesion extending from D3 to D9, partially occupying foramina D5-D6 and D6-D7 (Figure 1). The lesion has variable signal intensity with areas corresponding to fatty tissue and other to solid tissue. The mass caused marked compression of the adjacent spinal cord, which showed hyperintensity on T2 secondary to compressive myelopathy. After the administration of contrast, MRI displayed moderate signal enhancement. 


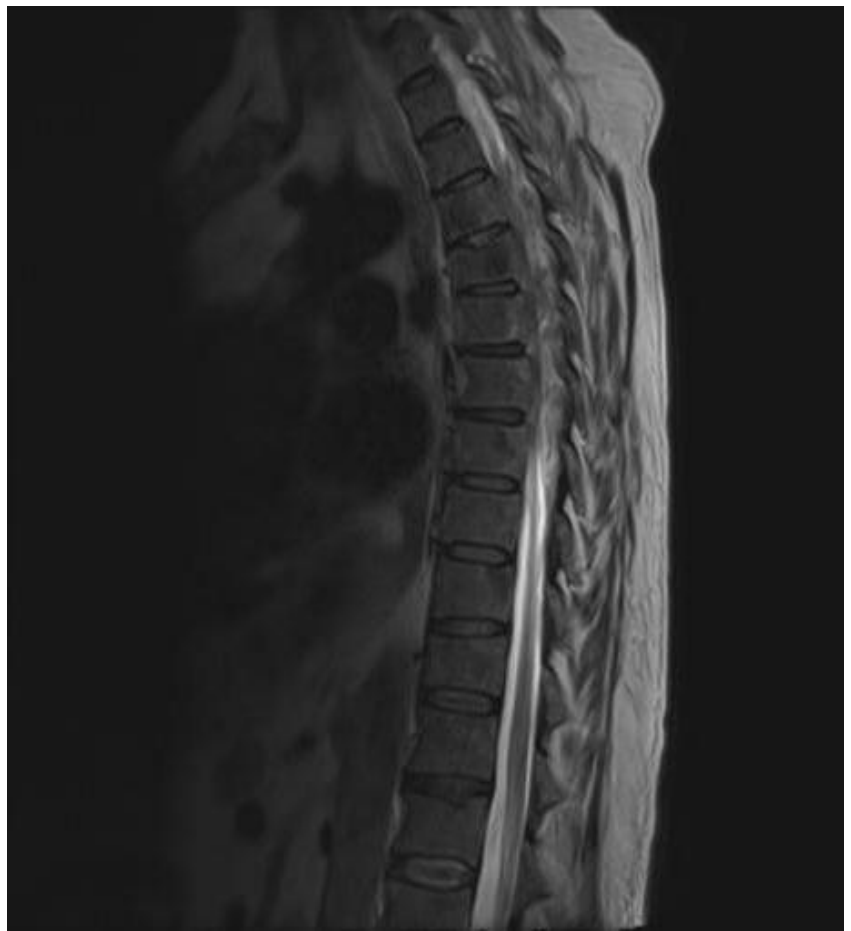

Figure 1: MRI T1 sagital and axial images showing a polylobulted mass extending from D3 to D9 level occupying the posterior part of the spinal canal. The mass caused marked compression of the adjacent spinal cord

Whole body CTscan showed also several bilateral paravertebral and paracostal nodules and a $39 \mathrm{x} 34 \mathrm{~mm}$ mass in the pre-sacro area all compatible with EMH, as well as a moderate splenomegaly $(16 \mathrm{~cm})$.

The patient underwent descompressive surgery with dorsal laminectomia (D3-D5) and partial lesion exeresis. Pathological findings showed bleeding fibroadipose tissue evolved and multiple areas of EMH (Figure 2). MRI lumbar and thoracic spine after surgery confirmed the removal of the segment elements D3-D6 with the presence of paraspinal nodular lesions already described in previous study.

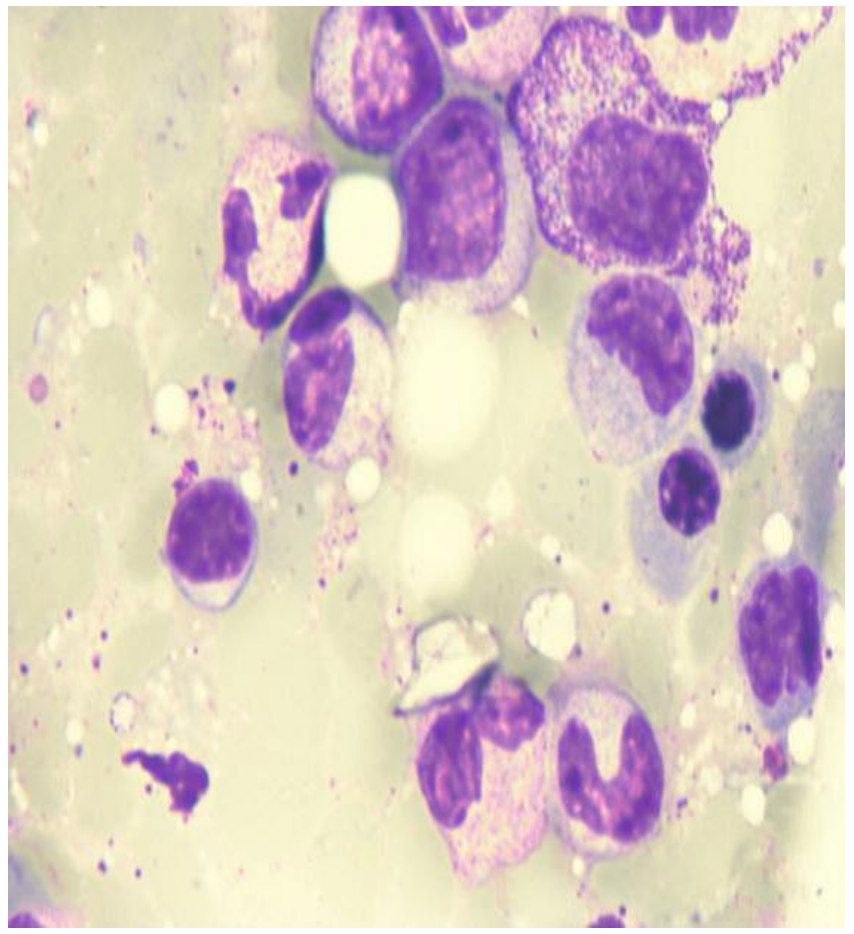

Figure 2: Histopathological findings (H\&E staining) showing hematopoeitic marrow precursors and fatty areas. Myeloid and erythroid precursors are shown at $100 \mathrm{x}$

The patient received radiation therapy to the affected area (30Gy in 15 fractions), and, the patient gradually regained muscle strength of lower limbs with rehabilitation exercises. Currently, the patient has recovered full mobility in lower limbs and is able to walk without impairment. 


\section{Discussion}

Spinal cord compression due to EMH has been reported as an uncommon complication in intermedia or major beta-thalassemia patients occurring mostly in children or young adults. In a recent meta-analysis, 43 cases reported in the last 10 years were reviewed and more than $95 \%$ of patients were young and the oldest was 44 years [7]. In fact, Tantawy et al, found spinal EMH in $13.3 \%$ of sixty young patients with intermedia or major beta-thalassemia [8]. Therefore, our case report is exceptional due to the age at presentation (63 years) in a patient with beta thalassemia minor without transfusion requirements.

This unusual case proves that long-term ineffective erythropoiesis in a minor beta-thalassemia can cause EMH in multiple localizations even in the absence of transfusion needing.

Another point to highlight is that even though symptoms had begun three years earlier, the neurological damage was fully reversed. In the series by Varlet et al, median time from symptoms to diagnosis was 3.3 months. Early diagnosis of EMH will affect the course of management and may reduce the incidence of irreversible neurological damage that would otherwise occur with prolonged undiagnosed cord compression [4]. Thus, physicians should be taken into account the diagnosis of a congenital anemia when evaluating neurological symptoms. Once diagnosed, there is not standard care in these cases and therapeutical alternatives such us radiotherapy, surgery, hyper-transfusion or hydroxyurea must be chosen in a case-by case- manner [6].

\section{References}

1. Eskazan AE, Ar MC, Baslar Z (2012) Intracranial extramedullary hematopoiesis in patients with thalassemia: a case report and review of the literature. Transfusion 52: $1715-20$.

2. Campisi S, Mangiagli A, De Sanctis V, Giovannini M (2011) Paraplegia in a thalassaemic patient with short stature. Pediatr Endocrinol Rev 2: $340-4$.

3. Savini P, Lanzi A, Marano G, Moretti CC, Poletti G, et al. (2011) Paraparesis induced by extramedullary haematopoiesis. Worl J Radiol 3: 82-4.

4. Haidar R, Mhaidli H, Taher AT (2010) Paraspinal extramedullary hematopoiesis in patients with thalassemia intermedia. Eur Spine J 19: 871-8.

5. Galati MC, Raiola G, De Sanctis V, Arcuri V, Arcuri PP, et al. (2008) Extramedullary haematopoiesis in beta thalassaemia--unusual presentations: case reports. Pediatr Endocrinol Rev 1: 140-3.

6. Moncef B, Hafedh J (2008) Management of spinal cord compression caused by extramedullary hematopoiesis in beta-thalassemia. Intern Med 47: 1125-8.

7. Varlet G, N'dri Oka D, Drogba KL, Haïdara A, Zunon-Kipré Y, et al. (2010) Beta-thalassemia intermedia complicated by spinal cord compression. Report of three cases and meta-analysis. Neurochirurgie 4: 315-23.

8. Tantawy AA, Adly AA, Mahdy SA, Kamel GZ (2009) Spinal cord compression and extramedullary hematopoiesis in young Egyptian beta-thalassemia patients. Hemoglobin 33: 448-62. 